University of Nebraska - Lincoln

DigitalCommons@University of Nebraska - Lincoln

$10-2010$

\title{
The Elasticity of Taxable Income during the 1990s: New Estimates and Sensitivity Analyses
}

Seth H. Giertz

University of Nebraska-Lincoln, sgiertz2@unl.edu

Follow this and additional works at: https://digitalcommons.unl.edu/econfacpub

Part of the Economic Policy Commons, and the Public Economics Commons

Giertz, Seth H., "The Elasticity of Taxable Income during the 1990s: New Estimates and Sensitivity Analyses" (2010). Economics Department Faculty Publications. 70.

https://digitalcommons.unl.edu/econfacpub/70

This Article is brought to you for free and open access by the Economics Department at DigitalCommons@University of Nebraska - Lincoln. It has been accepted for inclusion in Economics Department Faculty Publications by an authorized administrator of DigitalCommons@University of Nebraska - Lincoln. 
Published in Southern Economic Journal 77:2 (2010), pp. 406-433.

Submitted November 2007; accepted September 2009.

The author wishes to thank David Weiner, Ed Harris, Bob Dennis, Doug Hamilton, Tom Woodward, Emmanuel Saez, Chris Bollinger, and three anonymous referees for Southern Economic Journal for their comments and assistance.

\title{
The Elasticity of Taxable Income during the 1990s: New Estimates and Sensitivity Analyses
}

\author{
Seth H. Giertz \\ Department of Economics, CBA 368, P.O. Box 880489, University of Nebraska-Lincoln, \\ Lincoln, NE 68588- 0489 USA; email sgiertz2@unl.edu
}

\begin{abstract}
Over the past two decades, the elasticity of taxable income has emerged as the central parameter for assessing efficiency and revenue implications from changes to tax policy. This article estimates short- and longer-run responses of taxable (and gross) income to changes in tax rates using panels of U.S. tax returns for the 1990s. With the richest set of income controls, income-weighted elasticity estimates range from 0.19 to 0.33 , depending on whether responses are measured over one- or three-year intervals. An alternative approach designed to capture delayed and anticipatory responses yields much larger estimates - ranging from 0.43 over the short term and from 0.78 to 1.46 over the longer term. A continuing obstacle to identification encountered here is that the income controls most likely to control for mean reversion and divergence within the income distribution are also the most likely to absorb independent variation in tax rates, also needed for identification.
\end{abstract}

\section{Introduction}

Economists have long recognized that taxation creates economic inefficiency by distorting relative prices, often between leisure and all other goods in the economy. Even a broad-based income tax can have substantial efficiency costs, so long as leisure remains untaxed. Harberger (1964) uses this as motivation for comparing the efficiency implications of direct versus indirect taxation. In so doing, he shows how labor supply elasticities can be used to measure the efficiency implications of income taxation. ${ }^{1}$ Harberger's analysis had a profound influence on public and labor economists, spurring increased research into labor supply elasticities, which were seen as proxies for the efficiency costs from taxation.

More than two decades after Harberger, economists began to emphasize the variety of other margins over which taxes can distort behavior, in addition to hours worked. These economists noted that these other behavioral responses may too have important implications for efficiency. An important building block in the evolution of this literature was set forth by Slemrod (1990), who presented a hierarchy of behavioral responses to taxation. Slemrod divided behavior into three categories based on their responsiveness to taxes. His least respon-

1. Specifically, it is the compensated elasticity (or the substitution component of the overall elasticity) that is important for measuring efficiency. Compensated elasticities measure the portion of the overall response attributable to changes in relative prices (as opposed to the portion of the response due to changes in income). 
sive category, real responses, includes individuals changing consumption and work patterns and businesses altering investment and production decisions. Second, in order of responsiveness is circumvention, which includes both illegally (evasion) and legally (avoidance) bypassing the tax system. ${ }^{2}$ In the case of evasion, income is concealed from tax authorities - or factors that offset tax liabilities, such as expenses and deductions, are inflated (beyond what is legally permitted). In the case of avoidance, income is shifted in order to receive more favorable tax treatment. Diverting income into a tax-deferred retirement account is an example of avoidance. ${ }^{3}$ Included in circumvention is the expenditure (of time and money) necessary to avoid or evade taxation. Third on the hierarchy - and the most responsive-is the timing of income receipt, which includes "pulling" the receipt of income into the previous year or "pushing" it into the next in order to take advantage of more favorable tax treatment (while not altering real behavior). ${ }^{4}$ Slemrod further recognizes that the type of behavioral response could have implications for both tax revenue and tax incidence-and in some cases efficiency.

Predating Slemrod's insights, Lindsey (1987) produced elasticity estimates for taxable income-although what Lindsey termed taxable income more closely approximates adjusted gross income (AGI) - instead of labor supply. ${ }^{5}$ Lindsey's estimated elasticities were much larger than the labor supply literature would have suggested. Lindsey emphasized the revenue implications of the elasticity of taxable income (ETI) but not its efficiency implications.

Building on Slemrod and Lindsey, Feldstein (1995) produced ETI estimates but went much further than Lindsey in describing the behaviors that could affect taxable income. He argued that many of these behaviors were not captured by labor supply elasticities. Furthermore, Feldstein posited that (income) taxation creates economic inefficiency not only by distorting the relative price between labor and leisure but more broadly by distorting the relative price between goods or activities that are taxed and those that are not taxed since leisure is not the only untaxed activity. For example, in response to taxes, not only work hours but also work effort might change. Compensation can shift between taxed forms and untaxed forms. When tax rates are higher, more compensation is paid in tax-exempt fringe benefits instead of wages. And economic activity may shift from jurisdictions with more burdensome taxes to others where taxes are more favorable; evasion is another response to taxation that confers deadweight loss but does not imply increased leisure. Over the long run, taxes may also distort investment decisions, including how much education to pursue and in what occupations to specialize.

Next, Feldstein (1999) showed that the ETI along with information on marginal tax rates and income is all that is necessary to calculate changes in both tax revenue and efficiency. ${ }^{6}$

2. What I term "circumvention" Slemrod terms "avoidance responses." I use the former term because some authors use avoidance to refer only to legal maneuvers, which would not include evasion.

3. Following Slemrod and Yitzhaki (2002), "avoidance" refers to avoiding the tax but not avoiding the activity. For example, choosing leisure is one way to avoid paying income tax. but that decision falls under real substitution and not avoidance because the consumption bundle has changed as a result of the tax.

4. Here also, timing is another form of avoidance but is classified separately because the timing of income receipt is believed to respond differently to tax changes than other forms of avoidance (with respect to both the size and the persistence of the responses).

5. The elasticity of taxable income measures the percent change in taxable income associated with a $1 \%$ increase in the net-of-tax rate (NTR), where the NTR equals one minus the marginal tax rate (MTR). Sometimes the NTR is also referred to as the "after-tax share."

6. There are caveats to this, and, in many instances, assessing the efficiency and revenue implications from a tax change is complex. For example, suppose tax rates rise and, in response, taxable income falls, but a portion of that drop in taxable income is due to increased charitable contributions (and suppose those charities produce positive externalities). Or suppose that a tax increase is used to finance an underprovided public good. In any instance where fiscal externalities are present, assessing efficiency implications is more complex (Chetty 2009b). 
In Harberger's model, labor is the only source of income, all income is taxed when earned, and thus taxable income equals labor income; therefore, the ETI with respect to the tax rate is the same as the labor supply elasticity - or at least the elasticity of labor earnings since labor hours and labor earnings may be imperfectly correlated because of factors such as work effort.

The beauty of Feldstein's $(1995,1999)$ papers is that it is not necessary to separately measure all the underlying behaviors that influence taxable income. All these behaviors have efficiency implications, and, in equilibrium, the costs associated with a $\$ 1.00$ change to taxable income, at the margin, are always equal (to the marginal tax rate). However, more recent research highlights instances where the manner in which taxpayers respond could have important (efficiency and revenue) implications. And understanding the anatomy of behavioral responses is important for tax policy design. For example, on efficiency grounds, one may want to tax more heavily income sources that are least responsive to taxationjust as Ramsey (1927) suggests taxing goods proportionally to the inverse of their demand elasticities.

While Feldstein (1995) spawned dozens of subsequent papers and the ETI is now a central parameter in tax policy discussions, there is no consensus as to the size of the ETI. ${ }^{7}$ The earliest studies (Lindsey 1987; Feldstein 1995) suggested an ETI ranging between 1 and 3, although, as discussed later, most now believe that these early estimates are substantially biased upward. While the most widely cited ETI estimates are now much lower, often around 0.4 , credible estimates range from 0 to 1 - and some studies report estimates in excess of 1 for very high income groups. Where the ETI lies within this wide range of estimates has tremendous consequences for the efficiency and revenue implications from changes to tax rates. In fact, in examining the major components of the "Bush" tax cuts, Giertz (2009) uses a range of ETI estimates from the literature to show how allowing the individual income tax rate cuts to expire-scheduled to occur after 2010 - might affect economic efficiency and tax revenues. Giertz finds the deadweight loss per additional dollar of tax revenue from the increase in federal income tax rates to range from \$0.19 at an ETI of 0.2 to $\$ 1.72$ at an ETI of 0.8 - that is, an ETI of 0.8 implies nine times the deadweight loss (per dollar of additional federal revenue) than does an ETI of 0.2. Note that at an ETI of 0 , this measure equals 0 (i.e., changes to tax rates have no efficiency implications), and once the revenue-maximizing (or Laffer) tax rate is reached, this measure equals infinity. Giertz estimates that an ETI of 0.8 implies a total revenue offset of $63.3 \%$ versus $15.8 \%$ at an ETI of 0.2 (both compared to the potential gain in federal revenues with no behavioral responses). These estimates include offsets to payroll and state income taxes (whose bases overlap with the federal income tax base).

The majority of research in the U.S. taxable income elasticity literature has focused on the 1980s tax cuts. However, research that does exist on the 1990s suggests that responses for the two decades may be dissimilar. Giertz (2007) reports estimated elasticities for the 1990s that are over one-third smaller than analogous estimates for the 1980s. Additionally, work by Slemrod (1996), Goolsbee (1999), and Saez (2004) all suggests great variation in the ETI across time periods. However, Chetty (2009a) shows that variation in estimates across tax changes does not necessarily imply that the true ETI is changing over time but could instead reflect costs of reoptimizing. If taxpayers imperfectly optimize, Chetty shows that a range of ETI estimates could all be consistent with a single true ETI.

7. In fact, as Kopczuk (2005) and Slemrod and Kopczuk (2002) posit, the ETI is. at least to a degree, a choice variable and not a structural parameter. They argue that the ETI is a function of many factors, including the institutional features of a tax system, which establish rules for deductions and credits as well as policies toward evasion. 
This article revisits the 1990s tax increases using panels of Internal Revenue Service (IRS) tax return data for years 1984, 1985, and 1988-1995. These data heavily oversample high-income filers, which research suggests play a critical role in determining overall responses to changes in tax rates (Navratil 1995; Moffitt and Wilhelm 2000; Gruber and Saez 2002; Saez 2004). I find that when employing the richest set of income controls, estimates are larger for the longer term than for the short term. ${ }^{8}$ As is common in this literature, sample income cutoffs (or floors) are imposed in order to lessen influences from mean reversion on the estimates. When imposing a $\$ 50,000$ income cutoff, the income-weighted estimated ETI is 0.33 when measuring responses over three-year intervals compared to 0.19 when measuring behavior over single-year intervals. Including separate controls for both mean reversion and divergence in the income distribution substantially alters estimated ETIs over the longer term but not for the short term. Employing the specification favored by Gruber and Saez (2002) yields a negative estimated ETI when employing single-year differences; when differencing over three-year intervals. Gruber and Saez's specification yields an ETI estimate of 0.54 -the largest ETI estimate (from the specifications that include just one tax rate variable among the explanatory variables). An alternative approach that includes lead and lag tax rate changes produces a short-term elasticity estimate of 0.43 and a longer-term estimate ranging from 0.78 to 1.46 , Income weighting is important. Unweighted estimates are much smaller than income-weighted estimates and suggest at most a very modest ETI. This also suggests that the ETI increases with income- consistent with several other articles in the ETI literature.

A broader underlying conclusion from this article is that it is incredibly difficult to isolate responses to changes in tax rates from income changes due to myriad other complex factors. While flexible income controls are intended to control for both mean reversion and divergence within the income distribution, it is impossible to conclude that these problems are adequately mitigated. Furthermore, the flexibility of the income controls likely absorbs independent variation in tax rates (since income tax rates are also a function of income), which hampers identification.

\section{The Omnibus Budget and Reconciliation Acts of 1990 and 1993}

The two major tax changes examined in this article are the Omnibus Budget and Reconciliation Acts (OBRA) of 1990 and 1993. Both tax changes, for the most part, raised income tax rates on tax filers in the top $1 \%$ of the income distribution while not changing tax rates for those in the lower brackets.

As reflected in Figure 1, OBRA 90 raised the top federal marginal income tax rate from $28 \%$ to $31 \%$ beginning in 1991 . Additionally, the bill raised the cap on wages subjected to Social Security's hospital insurance tax - which is used to fund Medicare and amounts to $2.9 \%$ when including both the employee and employer share-from $\$ 53,400$ to $\$ 125,000$. The change in the cap resulted in higher MTRs on earned income for some in the top income decile but not

8. In most ETI studies, it is more accurate to refer to estimated elasticities as either "short term" or "longer term" (as opposed to "long term"). Long-term responses may be the most important but could take many years before responses are fully observed. These types of changes (which may include some human capital and occupation decisions as well as more traditional investment) are currently beyond the scope of the ETI literature. For that reason, this article eschews the label "long term" in favor of "longer term" in order to distinguish these estimates from short-term elasticities while also recognizing that they are not truly long term. 


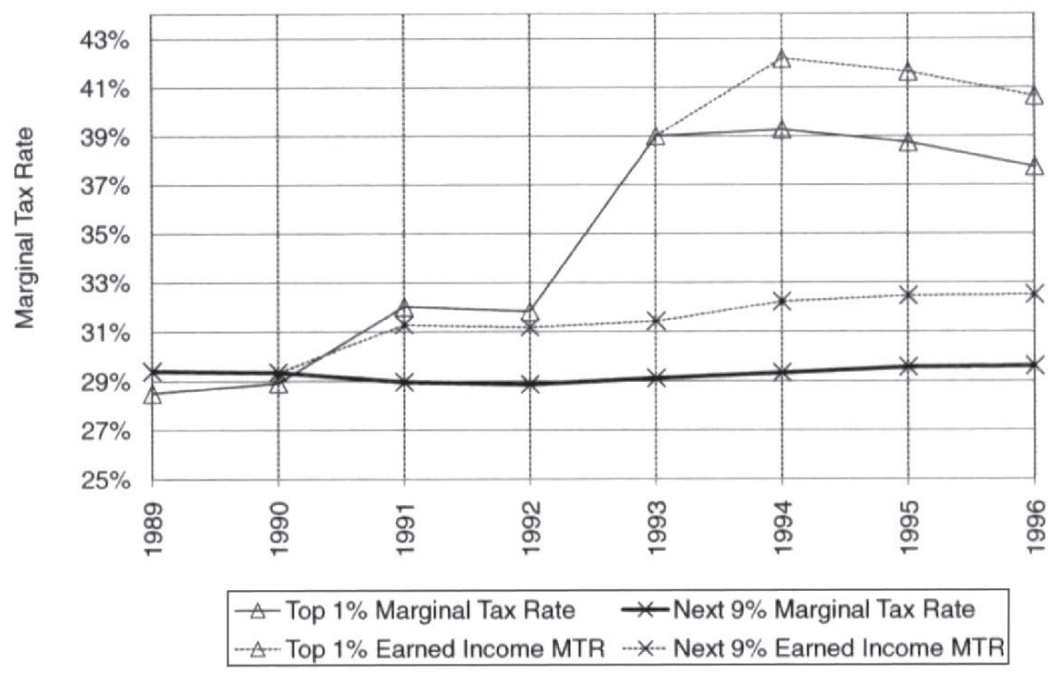

Figure 1. Effective Marginal Tax Rates.

Source: Effective federal income tax rates are from Saez (2004). Payroll tax rates are imputed by the author. State tax rates are not included.

for any in the top 1\%. The dashed lines in Figure 1 represent federal income plus payroll tax rates. While OBRA 90 generally raised tax rates for top income groups, the bill also lowered marginal tax rates for some filers. Filers in the so-called bubble bracket prior to OBRA 90 generally saw their marginal income tax rate fall from $33 \%$ to $31 \% .^{9}$

OBRA 93 created two new high-income tax brackets, at rates of 36\% and 39.6\%. Additionally, the cap on wages and salaries subjected to the Social Security hospital insurance cap was completely lifted. Those in the lower tax brackets were not directly affected by the bill's key provisions. OBRA 93's new tax brackets were retroactive and applied for 1993. The removal of the hospital insurance cap did not take effect until 1994. OBRA 93 represented a sharp increase in tax rates for the top 1\%, with the average effective NTR for the top $1 \%$ falling by about $15 \%$. Chetty (2009a) argues that if individuals imperfectly optimize, they are much more likely to respond to a tax change when the benefits of doing so are great. Chetty shows that, for top income groups, the benefits from reoptimizing in response to most tax changes over the past few decades would have only very modest benefits. In such instances, even modest "optimization frictions" (i.e., costs associated with reoptimizing) could imply an upper bound from an ETI estimate of 0 that exceeds 1 . With the exception of the Tax Reform Act of 1986 (TRA 86), OBRA 93 is the only tax change over the past few decades that, in the presence of optimization frictions, may yield ETI bounds for the top $1 \%$ that are meaningful.

\section{Data and Methods}

Data on individual tax returns for years 1984, 1985, and 1988-1995 are from the Statistics of Income (SOI). The SOI data are large stratified random samples of tax returns that heavily oversample high-income tax filers - in fact, sampling rates reach $100 \%$ for filers at the very

9. Prior to OBRA 90, those with incomes beyond the $33 \%$ bracket faced marginal tax rates of $28 \%$. These filers were moved to the $31 \%$ bracket after OBRA 90. 
Table I. Summary Statistics

\begin{tabular}{lrrr}
\hline & Year to Year $^{\mathrm{a}}$ & Three-Year Intervals & End Years \\
\hline $\begin{array}{l}\text { Paired observations } \\
\text { Differencing: years between base }\end{array}$ & 99,421 & 157,083 & 31,142 \\
$\quad$ and subsequent observation & 1 & 3 & 6 \\
Returns with base-year taxable & & & \\
$\quad$ income greater than: & & & \\
$\$ 1,000,000$ & 7006 & 26,128 & 6013 \\
$\$ 5,000,000$ & 1822 & 5775 & 1456 \\
Mean taxable income & $\$ 36,566$ & $\$ 34,877$ & $\$ 41,360$ \\
Mean gross income & $\$ 51,827$ & $\$ 55,749$ & $\$ 60,047$ \\
Mean federal tax rate & 24.1 & 23.6 & 24.6 \\
Mean state tax rate & 4.8 & 4.4 & 4.5 \\
Mean net-of-tax rate & 71.1 & 72.0 & 70.9 \\
\hline
\end{tabular}

Estimates are based on SOI data from 1989 to 1995.

a. The year-to-year sample excludes those who are not observed every year.

b. Incomes are expressed in 1992 dollars, as adjusted by the growth in gross income.

top of the income distribution. SOI data are compiled by the IRS and include all information reported on filers' tax returns, plus additional demographic information. SOI's panel data are confidential and not available to the public. ${ }^{10}$ A panel of tax filers (not used in this article) was made public for the years 1979-1990. This panel, the public-use version of the Continuous Work History Survey (CWHS), was balanced (with some minor exceptions) and thus did not oversample high-income groups - and throughout the income distribution generally maintained much lower sampling rates than the full SOI data set. A big drawback to the public-use CWHS, in addition to its ending in 1990, is the dearth of tax filers at the top of the income distribution. For some tax questions, this means that estimates for key parameters may be driven by just handful of filers. For example, the top income group examined by Feldstein (1995) using these data included just 57 observations. The absence of publicly available U.S. panel data since 1990 has severely limited the ability of academic researchers to study more recent tax changes - an obstacle that this article overcomes. For more background on SOI data, see the Appendix.

\section{Constructing Three Samples}

The analysis relies on three panels constructed from SOI data so as to conform to the three key methodological variants - that is, first-differenced observations are created by pairing observations over one-, three- and six-year intervals. Estimates based on differencing over a single year are intended to capture short-term responses (including the retiming of income receipt). The other intervals are used to estimate longer-term responses, after filers have more time to respond. The approach is presented in detail later in this section.

Table 1 presents summary statistics for each of the three samples. Each sample includes only filers with taxable income greater than $\$ 10,000$ whose filing status does not change over the sample period. The sample for the year-to-year analysis (designed to capture short-run responses to changes in tax rates) is composed of 99,421 paired observations (14,203 filers) and

10. The IRS's SOI division has recently implemented a program that may allow a limited number of researchers access to SOI tax return data while maintaining strict controls to ensure taxpayer privacy. 
spans the years 1989-1995. Mean taxable income (in 1992 dollars and adjusted by sampling weights) is 536,566 , and mean gross income is $\$ 51,827$. The sample is restricted to fliers present in every year from 1989 to $1995 .{ }^{11}$ This restriction should not be particularly important since, as discussed below, observations in the regression analysis are weighted by the inverse of their probability of appearing in the sample.

The next sample is used to capture longer-term responses by measuring changes over three-year intervals; thus, this sample includes base years 1989-1992 (i.e., the first year of each paired observation). The third sample uses just two years of data, comparing changing between end years 1989 and 1995. For these two samples, the flier must be present in the base and subsequent year, but the filers are not required to be present in every year (from 1989 to 1995). The sample based on differences over three-year intervals is composed of 157,083 paired observations. Mean taxable income is $\$ 34,877$, and gross income is $\$ 55,749$ (in 1992 dollars and adjusted by sampling weights). The sample used to examine behavior between end years includes 31,142 paired observations. Mean taxable income is $\$ 41,360$, and gross income is $\$ 60,047$ (in 1992 dollars and adjusted by sampling weights). For comparison, data from 1985 and 1989 are used to estimate ETIs for TRA 86. This sample used to evaluate TRA 86 includes 37,673 filers. $^{12}$

\section{Methodology}

Beginning with Feldstein (1995), the vast majority of panel studies examining the ETI have employed some form of differences-in-differences estimation. Simple first differences - comparing two periods (one before a tax change and one after) and then dividing the percent change in taxable income by the percent change in the NTR - would result in valid elasticity estimate if the only changes in income between the two periods were due to the tax change. However, many other factors also influence income. The task for identifying the tax response rests in finding a "control" group (used for the second difference) that is not subject to the tax change (or one that is subject to a different tax change). Of course, no true control group actually exists. Thus, a second-best solution becomes finding a pseudo control group that did not experience the same tax change and whose non-tax-related income trends are very similar. This is no simple task because mean reversion and non-tax-related income trends appear to have heterogeneous influences across the income distribution (see Piketty and Saez 2003). While both phenomena are characterized by income changes over time, there is an important distinction between them. Mean reversion refers to a "reshuffling" of the income distribution, while the distribution itself does not change. On the other hand, exogenous (non-tax-related) income trends refer to changes to the income distribution.

Even if income trends, absent tax changes, are heterogeneous when comparing groups experiencing a tax change to others not experiencing a change, the groups not experiencing a tax change may still serve as an effective control group if exogenous income trends for the two groups are similar after conditioning on control variables. Because these heterogeneous income trends were not well understood when the ETI literature emerged, the earliest studies did not attempt to control for this phenomenon. This likely biased estimates by Lindsey (1987) and Feldstein (1995) upward since the more rapid growth in income by those at

11. Filers in each sample must also be present in 1988 because data from this year are used in constructing the independent variables.

12. Auten and Carroll (1999) also employ a variation of this approach using similar data for the years 1985 and 1989. Their set of control variables and income restrictions are not the same, however. 
the top of the income distribution was positively correlated with an increasing NTR because top income groups generally experienced the largest decrease in their tax rates (i.e., increase in their NTRs). Mean reversion at the top would tend to bias estimates for the 1980s in the other direction; however, mean reversion did not affect Lindsey's study because he used repeated cross sections and not panel data. While Feldstein did use panel data, Slemrod (1996) and Gordon and Slemrod (2000) argue that his estimates may also have been biased upward due to income shifting from Subchapter $C$ corporations (which is generally not observed at the individual level) to Subchapter $S$ corporations (where income is taxed at the individual level and not subjected to the corporate income tax). For many upper-income taxpayers, corporate tax rates were lower than individual rates prior to TRA 86. while the reverse was true post-TRA 86.

\section{The ETI with Respect to the NTR versus the MTR}

With rare exceptions, the ETI literature measures elasticities with respect to the NTR and not the MTR. Maybe the NTR is favored because it is analogous to the wage rate often used in the labor supply literature. The (after-tax) wage rate is what a worker receives for an additional hour of work; the NTR is what a taxpayer keeps when receiving an additional dollar of taxable income. There is nothing inherently wrong with measuring responses with respect to the MTR instead of the NTR. However, comparing estimates with respect to the two different variables is not always straightforward, even though the two measures are related. The taxable income $(T I)$ elasticity with respect to the NTR can be expressed where $E T I_{1-\tau}=$ $[d T I / d(1-\tau)] \times[(1-\tau) / T I]$, which is equivalent to $-(d T I / d \tau) \times[(1-\tau) /(T I)]$. The corresponding elasticity with respect to the MTR is $E T I_{\tau}=(d T I / d \tau) \times(\tau / T I)$. Thus, $E T I_{\tau}$ multiplied by Z equals $E T I_{1-\tau^{\prime}}$ where $\left.Z \times(d T I / d \tau) \times(\tau / T I)=-(d T I / d \tau) \times[(1-\tau) / T I)\right]$ and $Z=[(\tau-1) / \tau]$. Note that simply multiplying estimates by -1 will often result in misleading comparisons.

\section{Regression Specification}

The estimating equation compares individual-level changes in income and NTRs measured over one-, three-, or six-year intervals. The equation is estimated via two-stage least squares and can be expressed as follows:

$$
\ln \left(\frac{\text { income }_{i t+k}}{\text { income }_{i t}}\right)=\alpha_{t}+\xi \ln \left(\frac{1-\tau_{i t+k}}{1-\tau_{i t}}\right)+f\left(\text { income }_{i t^{\prime}} \text { income }_{i t-1}\right) \beta+X_{i} \gamma+\varepsilon_{i t}
$$

The dependent variable is the log of income for individual $i$ in subsequent year $k$ (income ${ }_{i t+k}$ ) divided by income in base year $t$ (income ${ }_{i t}$ ), where the subsequent year is either one, three, or six years after the base. The key independent variable equals the log of the NTR in the same subsequent year $\left(1-\tau_{i t+k}\right)$ divided by the NTR in the base year $\left(1-\tau_{i t}\right)$, where $\tau$ is the sum of effective federal, payroll, and state MTRs. ${ }^{13}$ While the goal of the regression analysis is to identify the influence of tax rates on income, tax rates are also a function of income and thus not exogenous. This simultaneity issue is resolved by employing two-stage least squares and including an exogenous instrument for the NTR (whose construction is discussed later). The co-

13. In addition, Gruber and Saez (2002) include a variable to separate the income effect from the substitution effect. They conclude that the income effect is not important and thus exclude it from most of their analysis. 
efficient $\xi$ represents the ETI. In addition, the analyses also include year fixed effects $\left(\alpha_{t}\right)$ plus demographic information $\left(X_{i}\right)$, including age, gender, marital status, and itemization status. And functions of income in the base year and the year prior to the base $\left(\right.$ fincome $_{i t^{\prime}}$ income $\left.\left._{i t-1}\right)\right)$ are included in order to control for mean reversion and non-tax-related divergence in the income distribution.

Finally, an alternative approach is used to estimate both longer- and short-term elasticities. This specification builds on the year-to-year model by including as explanatory variables both a one-year lag and a one-year lead in the log change of the NTR, in addition to the concurrent log change in the NTR. The estimating equation becomes

$$
\begin{aligned}
\ln \left(\frac{\text { income }_{i t+1}}{\text { income }_{i t}}\right)=\alpha_{t} & +\xi_{0} \ln \left(\frac{1-\tau_{i t+1}}{1-\tau_{i t}}\right)+\xi_{1} \ln \left(\frac{1-\tau_{i t}}{1-\tau_{i t-1}}\right)+\xi_{2} \ln \left(\frac{1-\tau_{i t+2}}{1-\tau_{i t+1}}\right) \\
& \left.+f \text { income }_{i t^{\prime}} \text { income }_{i t-1}\right) \beta+X_{i} \gamma+\varepsilon_{i t}
\end{aligned}
$$

where $\xi_{1}$ and $\xi_{2}$ represent the coefficients for the lagged change in the NTR and the lead change in the NTR, respectively. This approach is similar to that employed by Goolsbee (2000) when examining behavioral responses by executives to the 1990s tax changes. (Goolsbee's approach has also been employed by Hall and Liebman [2000] and Eissa and Giertz [2006].) Goolsbee's data were in log form and not differenced (although, in some specifications, he includes individual fixed effects). He included the lead tax rate but not the lag. Goolsbee interpreted estimates for $\xi_{0}$ to be short-term (or transitory) responses and $\xi_{0}+\xi_{2}$ as the longer-term (or permanent) response. $\xi_{2}$ could account for behavioral changes in anticipation of a prospective tax change, which could either raise the longer-term elasticity or lower it by capturing an offsetting response that could counterbalance a one-time intertemporal reallocation of income. Analogously, $\xi_{1}$ could capture a delayed response to the tax change. In such instances, a broader measure of the ETI becomes $\xi_{0}+\xi_{1}+\xi_{2}$. Including the lead rate change might be particularly relevant for the 1993 tax increase since the tax change should have been anticipated; President Clinton campaigned on such an increase in the year prior to becoming president.

However, another plausible interpretation exists for the coefficients on the lead and lagged rate changes. Even excluding the possibility of a delayed tax response, the $\operatorname{lag}\left[\ln \left(\right.\right.$ income $_{t} /$ in $^{-}$ come $\left.\left._{t-1}\right)\right]$ is potentially important if, for example, the NTR falls from year $t-1$ to base year $t$ and individuals respond by shifting income from $t$ to $t-1$, making year $t$ income smaller than otherwise. If rates also change from year $t$ to $t+1$, this shifting could bias the estimated concurrent tax response. Analogously, the lead rate change $\left[\ln \left(\right.\right.$ income $_{t+2} /$ income $\left.\left._{t+1}\right)\right]$ instead of or in addition to capturing an anticipatory response, could account for income shifting (resulting from a concurrent tax response in another period) between the year $t+1$ and year $t+2 .{ }^{14}$ For example, suppose that for some the NTR falls between year $t+1$ and $t+2$; individuals may be induced to pull income back to $t+1$, making concurrent income growth (between $t$ and $t+1$ ) larger than otherwise.

14. Recall that in the 1990s, marginal tax rates (on earned income) increased for some taxpayers in both 1993 and 1994. 


\section{Income Measures}

Two different income measures are examined. The most comprehensive measure is gross income, where gross income $=$ total income - adjustments $^{15}-$ capital gains - supplemental (Schedule E) income or loss + dividends excluded from AGI + unemployment compensation not included in AGI + Keogh and traditional IRA contributions + forfeited interest penalties + alimony paid.

The other measure is taxable income, which equals gross income less exemptions and the greater of the standard or itemized deductions. Social Security benefits are excluded because they are not fully observed in all years. As with most studies in this literature, capital gains are excluded from the analysis. The relationship between capital gains realizations and tax rates is an important question; however, including capital gains in the income measure poses several complications. Capital gains are observed only when they are realized and not when they accrue-thus, changes in capital gains realizations do not necessarily reflect changes in investment. Capital gains realizations have proven extremely difficult to model and likely respond differently to changes in tax rates than do other income sources (see Congressional Budget Office [CBO] 2006). Burman and Randolph (1994) reconcile evidence from time-series data (showing only modest responsiveness of capital gains to changes in marginal tax rates) with evidence from individual-level data (finding very large elasticities). They argue that the smaller elasticities are picking up "permanent" (or longerterm) responses to tax rates, while the larger elasticities reflect transitory (or short-term) responses. ${ }^{16}$ Additionally, the tax rate applying to capital gains is often different from the rate applying to other income-although this could potentially be modeled by including a separate variable for changes to the capital gains tax rate. Note that over the period examined in this article, statutory federal tax rates on capital gains do not change. However, taxpayers may choose to realize gains in years when their other income is unusually low in order to take advantage of the lower tax rates.

Income measures are defined according to 1990 law and adjusted by growth in gross income, with 1992 as the point of reference. ${ }^{17}$ Over time, both tax rates and the definition of taxable income itself change. For example, deductions and exemptions permitted in some years are not allowed in others. The definition of income can affect responses to changes in tax rates (Slemrod and Kopczuk 2002). Additionally, Heim (2007) shows that changes to allowable exclusions and deductions can bias estimates, even when using a constant law definition of taxable income, unless the cross-price elasticities between activities whose tax status has changed and those that have not are zero-or known and taken into account. In contrast to the tax changes of the 1980s, the tax changes of the early 1990s were associated with only very minor changes to the definition of taxable income.

15. Adjustments are subtracted from total income to calculate AGI. Adjustments include certain education expenses, student loan interest, and contributions to traditional IRAs.

16. The massive increase in capital gains realizations prior to the implementation of the TRA 86 (which raised tax rates on capital gains realizations) is cited as evidence of the short-term responsiveness.

17. The adjustment for gross-income growth is analogous to adjustments that transform nominal dollars into real dollars. Thus, for this article, each individual's reported income is multiplied by the ratio of average gross income in 1992 over the average gross income in the year of the observation. 


\section{Short- and Longer-Run Responses}

The interval over which behavior is measured could have implications for the size of responses. Whether responses increase or decrease with time is theoretically ambiguous. For example, some real behavior and shifting between income sources may take time to respond. It may take years before labor and housing markets fully adjust to tax changes. Similarly, the behavioral literature suggests that people might delay altering their savings behavior (Madrian and Shea 2001). Furthermore, while income can be shifted between sources (e.g., between Subchapter $\mathrm{C}$ and Subchapter $\mathrm{S}$, as mentioned earlier), these decisions may be costly to reverse, and some may delay making changes until they better understand the costs and benefits of such changes. On the other hand, responses, such as the timing of income receipt, might respond immediately to a tax change, but these changes may be temporary - which could increase short-term ETIs without affecting longer-run ETIs.

The year-to-year analysis is intended to capture short-term behavior. Several have documented these timing responses for the 1990s (Parcell 1995; Feldstein and Feenberg 1996; Sammartino and Weiner 1997; Goolsbee 2000). Examining behavior over three-year intervals is intended to capture longer-term (or more permanent) responses. The end-year approach is also intended to focus on longer-term responses. By excluding observations from years adjacent to tax changes, this approach should not be influenced by timing responses. Using end years has the drawback that it excludes potentially valuable sources of variation. For example, data on income changes for other pairs of years (some for which tax rates did not change) may be helpful in constructing baseline income trends, which are necessary for identifying the tax response. In fact, Saez, Slemrod, and Giertz (2009) argue that in many circumstances it may be impossible to identify tax responses with just two years of data.

\section{Income Controls}

Saez, Slemrod, and Giertz (2009) highlight the obstacles that heterogeneous income trends and mean reversion pose to the identification of tax elasticities. If these phenomena are not accounted for, they are likely to overwhelm tax responses. ${ }^{18}$ Therefore, in addition to a specification with no income controls, six alternative controls are explored where (income $_{t}$ income $\left._{t-1}\right)$ in Equation 1 represents the following: ${ }^{19}$

A. The log of base-year income

B. The log of income in the year prior to the base year and the difference in logs between baseyear income and income in the year prior to the base

C. A 10-piece spline of the log of base-year income

D. A 10-piece spline of the log of income in the year prior to the base year and the difference in logs between base-year income and income in the year prior to the base

18. Because both phenomena are defined by income patterns, the variables used to control for them are both based on income (or lagged income). This makes it difficult to isolate the influence of each factor.

19. Alternatives A and C are the same as those employed by Gruber and Saez (2002). Alternatives B and D through F were employed by Kopczuk (2005). Both studies used the public-use version of the CWHS, focusing on the 1980s. 
E. The log of income in the year prior to the base year and a 10-piece spline of the difference in logs between base-year income and income in the year prior to the base

F. A 10-piece spline of the log of income in the year prior to the base year and a 10-piece spline of the difference in logs between base-year income and income in the year prior to the base.

Alternatives A and B include controls for either income in the base year or for both income in the year prior to the base and the change in income in the year prior to the base. Alternative $\mathrm{B}$ has the advantage over alternative $\mathrm{A}$ in that it includes separate controls for mean reversion and for divergence within the income distribution. However, both alternatives allow only for a linear relationship between the nontax factors and income growth. The CBO (2001), Piketty and Saez (2003), and others show heterogeneous rates of income growth across the income distribution during the past few decades (and including the 1990s). Growth rates are much greater (and more volatile) at the very top of the income distribution and do not increase linearly with income. For years 1989-1995, the share of income accruing to the bottom 99\% of taxpayers (whom for the most part did not experience a federal tax change and represent the potential "control" group pool) is relatively stable, decreasing by just $0.9 \%$, while the share of income accruing to the top $1 \%$ increases by $5.9 \%$ despite rising tax rates. This peculiarity in the evolution of the income distribution has reduced the efficacy of some otherwise sound econometric techniques - such as differences-in-differences. Diverging income trends suggests that income growth for a group not experiencing a tax change may be a poor counterfactual for another group that is experiencing a tax change. And the jaggedness of these diverging trends suggests that assuming that a group facing a tax change would have experienced income growth similar to what they had experienced over other years, when taxes did not change, may also be specious.

In the 1990s, when the NTR was generally falling for top incomes, imposing a linear control for income growth due to nontax factors (a nonlinear phenomenon) would likely attribute too little of the income growth at the top of the distribution to nontax factors. Those at the top of the distribution are one of the driving forces behind the overall response. Thus, linear controls, by overestimating the counterfactual income trend (i.e., the trend the "treatment" group would have followed had their tax rates not changed) at the top, likely underestimate the effect that rising marginal tax rates have on taxable income. However, without adequate controls, mean reversion will tend to bias estimates in the opposite direction. Bias from mean reversion in the left tail of the income distribution can be mitigated by, imposing a minimum income restriction on the sample. This technique cannot be used at the top of the income distribution because those at the top are the "treatment group" experiencing the tax change.

Alternatives $\mathrm{C}$ through $\mathrm{F}$ may do a better job because they include at least one nonlinear component (i.e., a 10-piece spline) that allows for non-tax-related income changes that vary by income decile. Alternative F has the greatest likelihood of adequately controlling for the nontax effects because it includes separate and nonlinear controls for both mean reversion and divergence within the income distribution. It is unlikely for these two separate phenomena to be adequately accounted for with just one variable (see Kopczuk 2005). However, the flexibility of the income splines is both a virtue and a vice. While the splines may control for the complex and heterogeneous secular trends across the income distribution, they may also absorb much of the independent variation in tax rates (see Feenberg 2009; Saez, Slemrod, and Giertz 2009), which in turn may severely hamper identification. Variation in changes in state tax rates may mitigate this problem. 
In addition to these controls, each specification is estimated after imposing income floors of $\$ 10,000$ and $\$ 50,000$ to the sample. The floors are imposed on only the base year of each paired observation. Imposing the floor on both the base and subsequent year could introduce bias since some near the threshold would be included in the sample if their income rose but excluded if it fell. Because the tax changes target upper-income filers, these floors will not exclude those experiencing a federal tax change but will alter the sample of filers used to identify counterfactual behavior (absent a tax change) ${ }^{20}$ Recall that mean reversion is especially pronounced at the tails of the distribution.

\section{Tax Rate Imputations and Instruments}

Federal marginal tax rates from income and payroll taxes are imputed using the CBO's federal tax model, and state rates are imputed using Bakija's state tax calculator (Bakija 2009). An instrument for the NTR is constructed by inflating base-year income by the growth in mean gross income over the (one-, three-, or six-year) interval between the base and subsequent year. Next, the tax calculator computes counterfactual tax rates based on the inflated income measure. The tax calculator does not simply match tax returns to a federal tax bracket. It is much more sophisticated and takes into account many of the intricacies of the tax code (such as phaseouts), which can lead to a difference between statutory and effective MTRs. While the instrument is exogenous because it is not influenced by behavior between the base and subsequent year (of each paired observation), it does not perfectly reflect what tax rates would have been had a tax change not occurred. The same obstacles that make it difficult to predict what income would have been absent a tax change (e.g., mean reversion and divergence across the income distribution) also make it difficult to predict what MTRs would have been since these are also a function of income.

In section 4, tax rates always include state, federal, and payroll taxes. A couple of studies have compared responses to state rates to responses from federal rates. For the 1980s, Gruber and Saez (2002) and Giertz (2007) report nearly identical estimates (of around 0.4) independent of whether they include only variation from federal tax rates or variation from both federal and state rates. When including only variation from state rates, however. Gruber and Saez report a much larger ETI estimate of 0.63 -although, this estimate is not statistically different from 0. Employing a much larger data set, Giertz reports a statistically significant estimate of 0.34 when including only variation from state rates. For the 1990s, Giertz finds a similar pattern - reporting an estimate of 0.11 (although not statistically significant) when including only variation from state rates and an estimate of about 0.2 both when including only variation from federal rates (and when including both federal and state rates). Gruber and Saez explain their larger estimated response to state rate changes by suggesting that state taxes could influence migration patterns (between states) and income shifting between states. Another possibility, consistent with Giertz's finding, is that migration could result in the capitalization of state tax changes in pretax incomes. Thus, instead of falling in response to a state tax increase, for example, out-migration may result in higher pretax equilibrium wages - that is, state tax rates may be endogenous.

20. The income cutoffs are based on gross income in 1992 dollars. The $\$ 10,000$ cutoff is similar to the restriction imposed by Gruber and Saez (2002). The $\$ 50,000$ cutoff is similar to that used by Carroll (1998). A $\$ 30,000$ income cutoff was also employed, but these results are not presented. In most cases, estimates when employing a $\$ 30,000$ income cutoff lie in between similarly estimated coefficients when employing $\$ 10,000$ and $\$ 50,000$ income cutoffs. In general, these estimates are closer to those found when using a $\$ 50,000$ income cutoff. 


\section{Income Weighting}

Beginning with Gruber and Saez (2002), several articles in the ETI literature weight regressions by income. Income weighting weights the data by each filer's base-year income. Thus, an income-weighted ETI should reflect the percent change in total taxable income (associated with a $1 \%$ increase in the NTR) - instead of the average of individual percent changes. For example, consider two taxpayers; Person 1 has income of $\$ 10,000$, and person 2 has income of $\$ 1$ million. In response to a $1 \%$ decrease in the NTR, suppose that person 1 reduces his income (by $0.2 \%$ ) to $\$ 9,980$ and that person 2 's income falls (by $1 \%$ ) to $\$ 990,000$. In this instance, the unweighted ETI equals $0.60 \times[(0.2+1) /(2)]$, whereas the income-weighted measure is nearly two-thirds larger, at $0.99 \times\{100 \times[(20+10,000) /(10,000+1,000,000)]\}$.

A meaningful average overall ETI must take into account the correlation between income and the elasticities. Income weighting does this by placing much more emphasis on responses at the top of the income distribution and, thus, is designed to yield results that are indicative of the overall income response (and tax revenue change) resulting from a change in tax rates. Note that if responses do not vary by income, then weighting will not affect ETI estimates. However, research consistently finds that estimated ETIs rise with income. ${ }^{21}$ If responses vary by income, a single overall elasticity will not be applicable when considering the impact of rate changes that target only part of the income distribution or for rate changes that differ across the distribution.

\section{Sample Weighting}

While some of the regressions are weighted by income, all regressions are weighted to adjust for the nonrandom sampling properties of the SOI data. Selection into the SOI data set is conditional on several factors, including income. Sampling probabilities reach $100 \%$ for very high income filers. The sample is also constructed such that once a filer is sampled, he will continue to be sampled in all subsequent years, so long as his income increases (and his other characteristics, such as filing status, do not change). In fact, the probability that one is observed in two different years is simply the minimum of the sampling probabilities for the two years. Without weighting, that sampling strategy raises the potential for spurious correlation between the dependent variable $\left[\ln \left(\right.\right.$ income $_{i t+k} /$ income $\left.\left._{i t}\right)\right]$ and the independent variables, including the tax variable. To avoid that possibility, (paired) observations are weighted by the reciprocal of their probability of appearing in the sample. That strategy is discussed in Auten and Carroll (1999), who also employ the strategy using SOI data. ${ }^{22}$

21. People with higher incomes generally have more opportunities to respond to tax changes. They generally itemize their tax returns, rely less on wage and salary income, and have more control over the timing and sources of their income than do other groups. People with more modest incomes can change their labor supply or alter the degree to which they use certain deductions and exemptions but likely have relatively few alternatives to alter their taxable income.

22. Income weights that account for the sample design are produced by simply multiplying income by the weights used to adjust for the SOI's nonrandom properties. Within a least-squares framework, weighted estimates are produced by minimizing the sum of squared errors multiplied by the square root of the weights. 


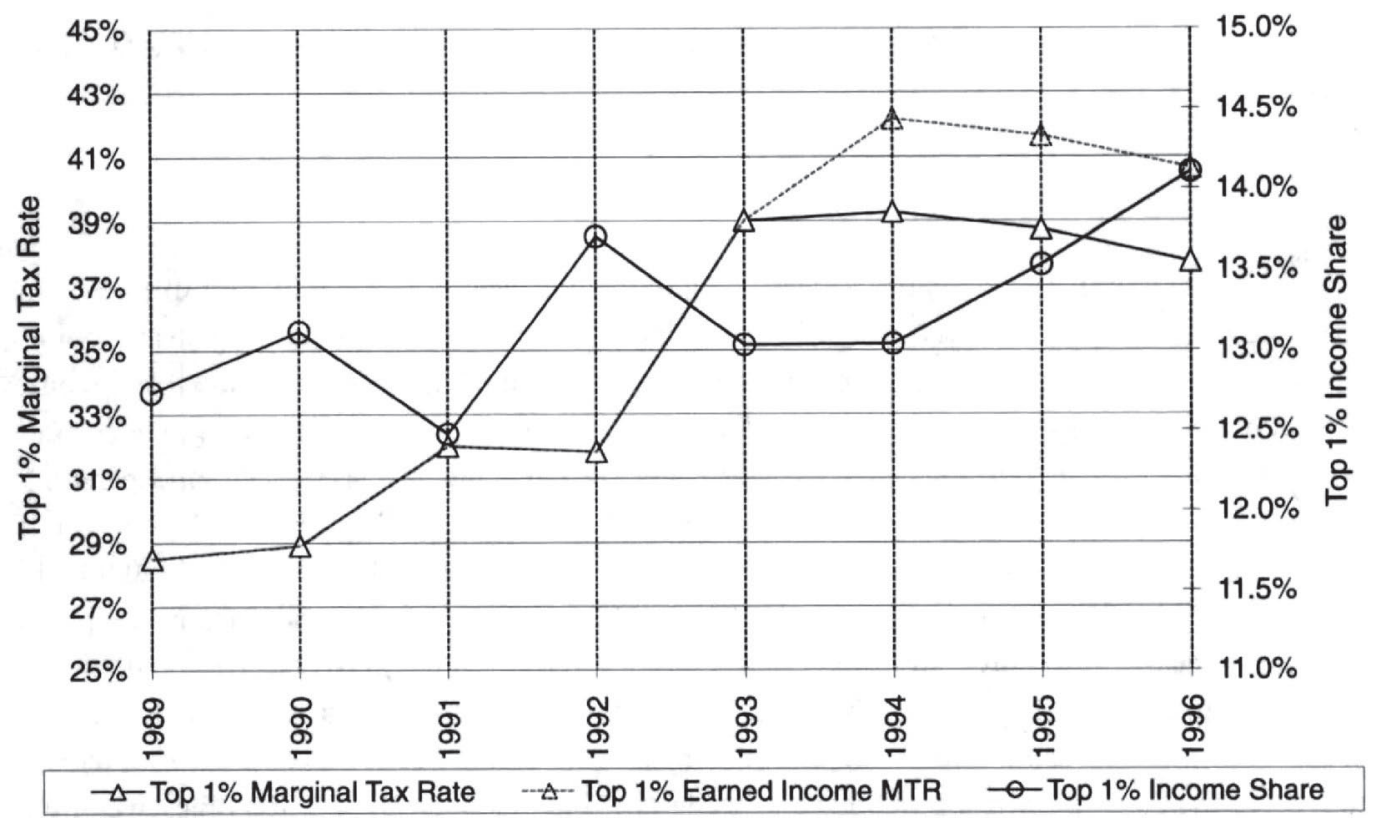

Figure 2. Top 1\% Income Share and Effective Marginal Tax Rate

Source: Effective federal income tax rates and income shares are from Saez (2004). Income excludes realized capital gains. Social Security, and unemployment benefits. Payroll tax rates are imputed by the author. State tax rates are not included.

\section{Results}

Figure 2 presents income shares and marginal tax rates for the top 1\% of taxpayers who were the focus of the 1990s tax increases. Consistent with findings reported by Parcell (1995), Sammartino and Weiner (1997), and Saez, Slemrod, and Giertz (2009), Figure 2 suggests a clear short-term behavioral response but not necessarily a longer-term response-while also exhibiting patterns that highlight the difficulty in finding robust estimates of behavioral responses.

Note that while the top one percent's share of income rises by 10.7\% from 1989 to 1996, their share of income decreases sharply from 1990 to 1991 and from 1992 to 1993, the years in which top tax rates increase. The spike in income shares in 1990 and 1992 suggests these taxpayers shifted income to the year prior to the tax increase. As rates on earned income increase further from 1993 to 1994, the share of income held by the top 1\% is flat, possibly suggesting that it is more costly to shift earned income than other income sources. Further note that, from 1989 to 1990 and from 1994 to 1996 (i.e., years that do not precede a tax increase), the share of income accruing to the top $1 \%$ increases sharply - and, as alluded to earlier, this upward trend appears to dominate any longer-term behavioral responses from the tax increases. While the trend in the income share at the top, when tax rates are not changing, is decidedly upward, the trend for those below the top $1 \%$ is flat. ${ }^{23}$ Even the next $9 \%$ of the income distribution (which was not affected by the increased income tax rates but was modestly affected

23. Of course, income shares arc a relative measure, and gains for the top $1 \%$ must be exactly offset by losses to the rest of the distribution. However, the gains are concentrated primarily within the top $1 \%$ of the distribution, while the (relative) losses are spread over the other 99\%, a much larger group. 
by the raising of the health insurance tax cap) does not show signs of the income shifting (in the years surrounding the tax changes) evident in Figure 2; over the seven years, patterns for the next $9 \%$ are pacific by comparison, trending upward slightly (see Saez 2004). Because Figure 2 is based on repeated cross sections - that is, it focuses on the top $1 \%$ in each year, independent of where these filers fell in the income distribution in other years - it is not influenced by mean reversion. On the other hand, panel data analysis is influenced by mean reversion since a filer in the top $1 \%$ of the distribution in a base year could be below the top $1 \%$ in the prospective year. Because of mean reversion, year-to-year income changes for those (starting) in the top $1 \%$ are about 6.5 percentage points lower for the panel than for the cross section. And, as the distance between the base and subsequent year increases, this difference tends to widen. For upper-income groups below the top $1 \%$, the impact of mean reversion is substantially subdued.

While the patterns in Figure 2 are consistent with behavioral responses to the 1990s tax increases, this evidence (from repeated cross sections) is suggestive at best, given the number of factors that influence income, which are uncontrolled for. The regression analysis will attempt to sort out these factors. However, the volatile nature of top incomes and the heterogeneous income trends across the distribution suggest that, even with sophisticated controls (see the previous section), identification may be tenuous.

Next begins discussion of the regression results by focusing on a specification that excludes any income controls. These estimates are clearly not identified because of unobserved heterogeneity; however, focusing first on these estimates may serve as a good starting point before examining the more sophisticated models. Next, focus shifts to income-weighted estimates from the specification with the richest set of income controls. Then these estimates are compared to estimates from specifications that employ alternative income controls. Finally, the section examines the implications of income weighting the estimates and the influence from adding adjacent-year rate changes to the model. Before proceeding, recall that, consistent with the vast majority of the ETI literature, elasticities are estimated with respect to the NTR (i.e., $1-\tau$ ); thus, theory predicts that elasticity estimates should be greater than or equal to zero.

\section{Estimates without Income Controls}

The first row of Table 2 presents income-weighted ETI estimates when including no income controls - but including demographics. The first row of Table 3 presents analogous unweighted (i.e., not income-weighted) estimates. Over both one- and three-year intervals, the estimates are somewhat larger when imposing the higher $\$ 50,000$ base-year income cutoff (for inclusion in the sample). This is consistent with mean reversion in the left tail. Some at the bottom of the distribution experience income increases because they are initially well below their average (or permanent) income-possibly because they are in school or for other reasons are not fully employed. Since this group does not experience a tax change, they are part of the "control" group, and thus mean reversion biases the baseline income trend (i.e., the trend absent tax changes) upward. When the NTR is falling, this will bias ETI estimates downward.

A second observation from the first rows of Tables 2 and 3 is that the estimated ETI increases as the interval over which behavior is measured is increased. With a $\$ 50,000$ income cutoff, the estimates rise from (a statistically insignificant) 0.2 when measuring behavior of single-year intervals to 1.57 and 1.78 when measuring behavior over three- and six-year intervals, respectively. This (again without income controls) suggests very large longer-term 


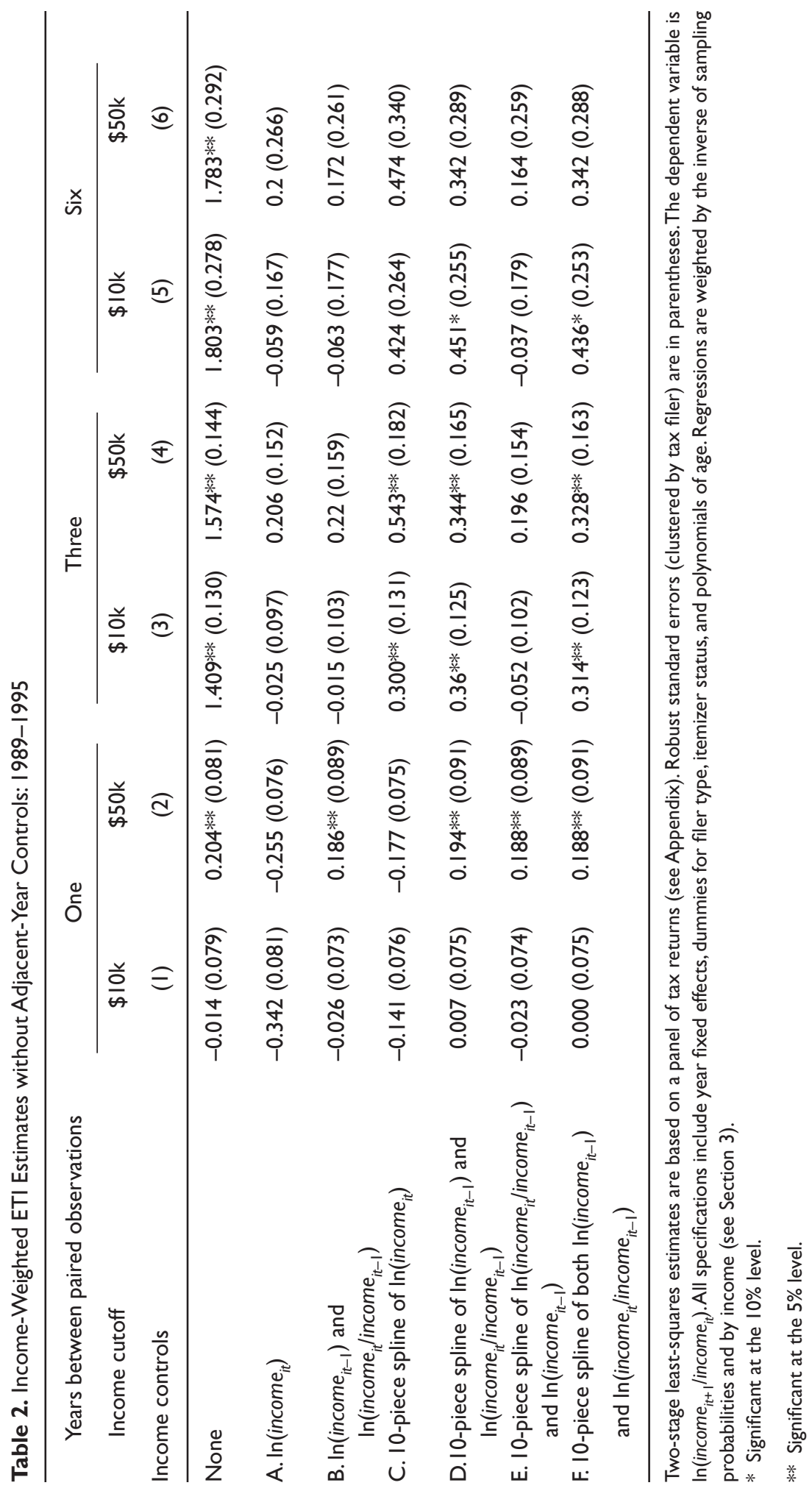




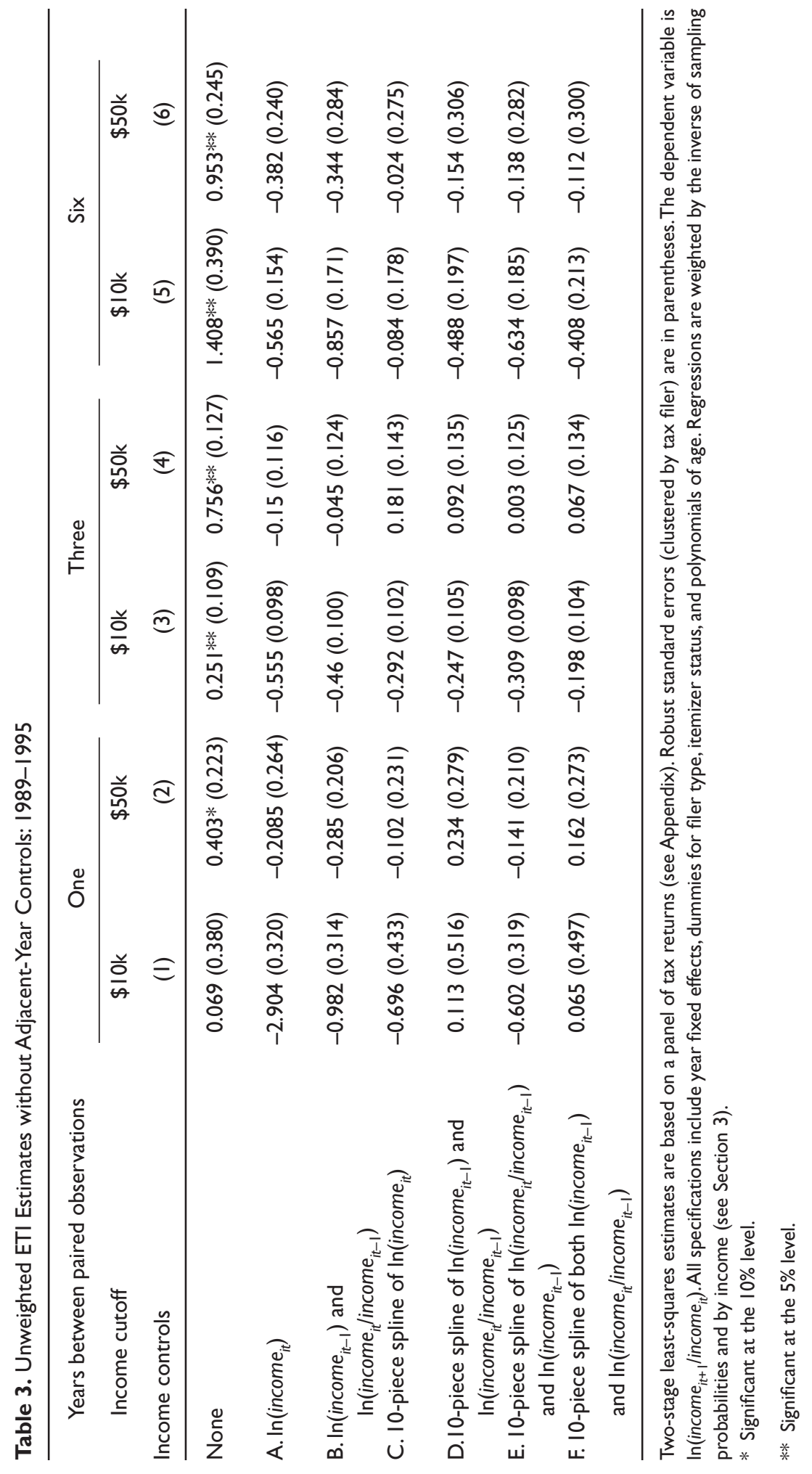


responsiveness and modest short-term responsiveness, which is seemingly inconsistent with the patterns in Figure 2. However, here the difference likely results from mean reversion at the top of the income distribution. Recall that Figure 2 is based on repeated cross sections of data (so mean reversion is not present) and that, with panel data, mean reversion is more severe the greater the time between observations. For the period examined in this article, Kopczuk, Saez, and Song (2010) find that from a group initially in the top 1\% of the income distribution, roughly $78 \%$ will remain in the top $1 \%$ after one year, $70 \%$ after three years, and $65 \%$ after five years. Thus, while Figure 2 suggests larger short-term (and smaller longerterm) elasticities, over the longer interval, mean reversion (of top incomes) in the panel data more than offset this. Note that the biggest mean-reverting income drops are at the top of the income distribution (i.e., the "treatment" group) and many times will be spuriously correlated with a falling NTR.

In the context of the ETI literature, the end-year approach without income controls is (among the approaches explored in this article) procedurally the closest to the approach applied by Feldstein (1995) to TRA 86. There are substantive differences between the two approaches; however, both rely on two years of panel data, employ differences-in-differences, and do not include additional controls for mean reversion or divergence in the income distribution. It is noteworthy that this approach results in very large estimates (about 1.8 with income weighting and from 0.95 to 1.41 without income weighting). These estimates are similar in magnitude to Feldstein's - even though MTRs are rising in the 1990s and falling after TRA 86.

\section{Estimates with the Richest Set of Income Controls (Specification E)}

Employing the richest set of income controls (i.e., the two 10-piece splines) and imposing a \$50,000 income cutoff (which mitigates mean reversions at the left tail of the income distribution without removing observations from the "treatment" group experiencing the tax increases) yields income-weighted estimated ETIs ranging from 0.19, when measuring responses over single-year intervals, to 0.33 , when measuring responses over three-year intervals. When lowering the income cutoff to $\$ 10,000$, this range now spans from 0 to 0.31 . In all but two cases, lowering the income cutoff and employing either one- or three-year differences yields lower estimated elasticities - in some cases substantially lower. As discussed in section 3, for the 1990s, the effect of lowering the income cutoff is primarily to expand the "control" group not experiencing a tax change. With the lower-income cutoff, mean reversion in the left tail may bias counterfactual income growth rates (for those experiencing a tax change) upward, which will bias ETI estimates downward, in, for example, the 1990s, when the NTR (for top income groups) is falling (see row F of Table 2). The general finding that longer-term estimates are somewhat larger than for the shorter term, which is also evident when imposing the richest set of income controls, is consistent with findings by Heim (2007) for the 1990s. But it is in contrast to findings by Sammartino and Weiner (1997) and Goolsbee (2000), who, for OBRA 93, find evidence of large short-term (or transitory) responses and much less evidence of a substantial longer-term response. It may be that the controls used here effectively separate the non-tax-related income trends from the tax effect, and the longer-term response is in fact larger (than for the shorter term), in which case it may be that many filers arc limited in their ability to respond to taxes in the short run, but over the longer term they have time to respond by recharacterizing income, changing jobs and investment decisions (including investments in human capital). However, the possibility that these controls do not fully account for mean reversion at the top cannot be ruled out-in which case residual mean 
reversion could be biasing estimates upward, with the bias increasing with the interval between paired observations. This is what was observed (to a much larger degree) in the specifications that exclude income controls.

When measuring behavior over a six-year interval, the estimated ETI (when imposing the $\$ 50,000$ income cutoff) is almost the same as the estimate using three-year intervals; however, the standard errors are much larger, and that estimate is not statistically different from 0 . In fact, estimates in this article (for the 1990s) that use just the two end years are almost always statistically insignificant. This reinforces a conclusion from Saez, Slemrod, and Giertz (2009, p. 25) that "no convincing estimates of the ETI can be obtained with a panel analysis using only two years of data when the tax rate changes are concentrated in a single part of the distribution."

For comparison purposes, the end-year analysis is repeated for TRA 86, using years 1985 and 1989, These estimates here are often statistically significant. With the richest set of income controls (specification F), the income-weighted estimates range from 0.39 , with a $\$ 10,000$ income cutoff, to 0.67 . with a $\$ 50,000$ income cutoff Rate changes from TRA 86 were substantial and changed by different amounts across a broad range of the income distribution and thus were not concentrated in one part of the income distribution. This additional cross-sectional variation may allow for more precise estimates for TRA 86, even with just two years of data. Another difference between the end-year approaches is that the interval between the start (1985) and end year (1989) is four years for the 1980s and six years for the 1990s (19891995). The greater the interval between paired observations, the more likely it is that unobserved factors are having a substantial influence on income growth. However, even when applying the end-year approach to years 1992 and 1993, Saez, Slemrod, and Giertz (2009) report estimated elasticities (for AGI) that are not robust-in fact, with flexible income controls, their estimates are negative (i.e., the "wrong" sign) and very large in absolute magnitude. Finally, while the standard errors are more modest for the 1980s, that does not mean that responses are accurately identified or robust. In fact, estimates from the ETI literature on the 1980s are not particularly robust. In the remainder of this article, little attention is paid to the end-year approach for the 1990s. The large standard errors found here (for the 1990s) limit inferences that can be made about the size of the ETI from this approach.

\section{Sensitivity to Income Controls}

Employing alternative income controls yields a range of estimated ETIs ${ }^{24}$ (see Table 2 and Figure 3). Figure 3 presents the estimated coefficients from Table 2 graphically in order to better visualize how the estimates vary depending on income controls, income cutoffs, and the number of years over which behavioral changes are measured. For the short term, the elasticity estimates are negative when including base-year income either in log form or as a 10-piece spline of the $\log$ (specifications $\mathrm{A}$ and $\mathrm{C}$ ) - two approaches employed by Gruber and Saez. With a $\$ 50,000$ income cutoff, the other three alternatives (B, D, and E) yield short-term ETI estimates that are almost identical to the estimate from specification $\mathrm{F}(0.19)$, which includes two 10-piece splines (see the second group of estimates in Figure 3). Each of these three alternative specifications includes separate controls for mean reversion and divergence in the income distribution but differs as to whether the controls are in spline form or as single logged variables. For the year-to-year analysis, it is surprising that the flexibil-

24. These estimates are compared to estimates that employ the most comprehensive set of income controls - that is, 10- piece splines of both the log of lagged income and the log change between base-year income and the lag. 


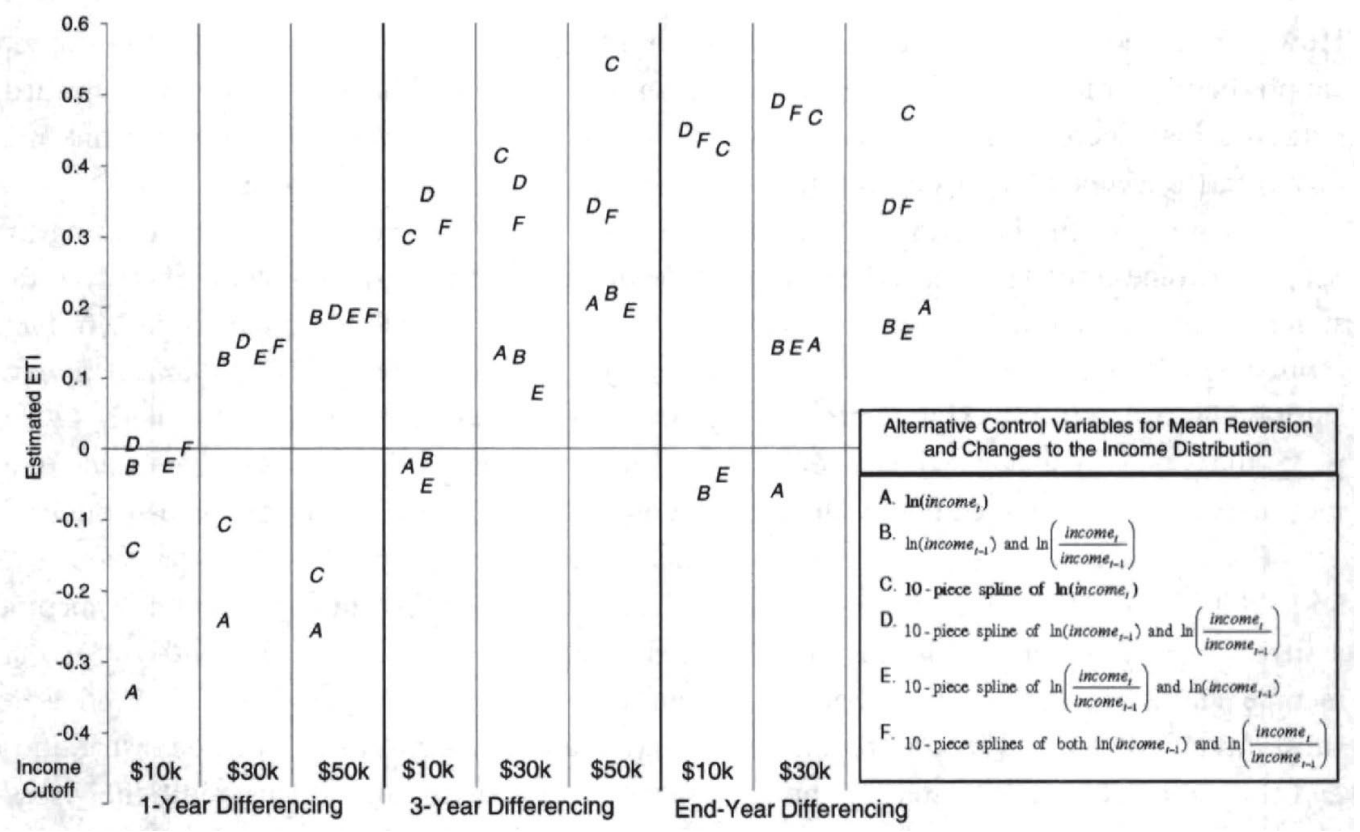

Figure 3. Income-Weighted ETI Estimates for the 1990s

Source: Estimates are based on Statistics of Income data for years 1989 to 1995. Estimates are from 2SLS regressions. Regressions are weighted by the inverse of sampling probabilities and by income (see Section 3).

ity of the spline to control separately for differing trends across the income distribution has virtually no effect on the estimates or standard errors. These estimates, when including both sets of income controls, are smaller than both the 0.38-0.56 range reported by Carroll (1998) and the 0.46 estimated by Heim (2007) - all of which are also based on year-to-year differences for the 1990s. However, Carroll does not weight estimates by income, and both studies employ different sets of control variables. Carroll does not include nonlinear income controls but does include industry and occupation dummies. His methodology also deviates from mine in a couple of other respects - including the approach for imputing tax rates and the construction of the instrument for the tax rate. Heim includes flexible income controls based on average income measures. In a sensitivity test, he employs a specification very similar to my specification $\mathrm{F}$ (which includes separate nonlinear income controls), reporting a statistically insignificant estimate of -0.08 . As discussed shortly. Heim includes data from 1987 in his analysis - the implementation year for TRA 86-which may account for the difference between his estimate and mine.

In comparison to my longer-term ETI estimate of 0.33 (specification F), Gruber and Saez's controls (specifications A and C), when imposing a $\$ 50,000$ income cutoff, yield incomeweighted estimated ETIs of 0.2 and 0.54 , respectively - with only the second of these statistically different from 0. Employing Gruber and Saez's richest specification (specification C), my estimate of 0.54 falls to 0.3 when lowering the income cutoff from $\$ 50,000$ to $\$ 10,000$ (Gruber and Saez's cutoff). Interestingly, when expanding the range of the data (from $1989^{25}$ to 1995)

25. Data from 1988 are included only in specifications B, D, E, and F, all of which include variables based on lagged income. 
to extend from 1988 to 2001, Giertz (2007) reports a longer-term estimated ETI of 0.2 for specification $C$ when employing a $\$ 10,000$ income cutoff. The difference between these estimates could be driven by the inclusion of base year 1988 (which includes variation in tax rates) but more likely results from the inclusion of years after 1995, which could alter the estimated baseline income trend. From 1996 to 2000, the share of income accruing to the top $1 \%$ grew (at an annualized rate) over four times as fast as it did during years 1989-1995 (Piketty and Saez 2003) - while federal statutory tax rates (applying to ordinary income) remained unchanged. Heim (2007) also produces estimates based on differencing over three-year intervals. His most preferred specification yields an ETI estimate of 0.58. However, when excluding years 1987 and 1988, this estimate jumps to 1.58 . Note that 1987 and 1988 were important phase-in year for TRA 86 where top marginal tax rates fell substantially.

My other three specifications (that again include separate controls for mean reversion and divergence in the income distribution but differ as to whether these variables are included as splines or logged variables) yield longer-term estimates ranging from 0.2 to 0.34 . The only statistically significant estimate from these three alternatives is 0.34 (specification D), which is from the model that includes the log change between lagged and base-year income in spline form and the log of lagged income as a single variable. Adding the second control in spline form (specification F) does almost nothing to the estimated ETI or standard error. Note that statistical significance varies across the choice of income controls because of changes to the estimated coefficient and not because of changes to the precision of the estimates. Standard errors vary little across these specifications.

\section{Sensitivity to Income Weighting and to the Definition of Income}

Following Gruber and Saez (2002), most panel studies focus on the ETI income-weight regressions. Recall from the previous section that, if the ETI is independent of base-year income (and the model adequately controls for other factors), income-weighted and unweighted estimates should be the same. In contrast to Table 2, Table 3 reports unweighted ETI estimates that are either negative (contrary to theory) or modestly positive. See also Figure 4, which is analogous to Figure 3 but presents unweighted (instead of income-weighted) estimates. For specifications that include income controls, estimates are never both positive and statistically significant-and, in general, standard errors are much larger for the unweighted estimates. A comparison of Tables 2 and 3 is consistent with findings throughout the literature that the ETI increases with income. More precisely, because the 1990s tax increases targeted the top $1 \%$ of the income distribution, the comparison of unweighted and income-weighted estimates suggests that within the top 1\%, the ETI increases with income. With the richest set of income controls (two 10-piece splines), unweighted ETI estimates, when imposing a $\$ 50,000$ income cutoff, range from 0.16 when measuring responses over one-year intervals to 0.07 when measuring responses over three-year intervals. Not only are these estimates much smaller than the comparable income-weighted estimates of 0.19 and 0.33 , respectively, but without income weighting, the estimated short-term elasticity is larger than the longer-term estimate - the reverse of the income-weighted finding. However, because the unweighted estimates are not statistically significant (standard errors for the unweighted year-to-year estimates are three times as large as for the income-weighted specification), little can be inferred from this finding. 


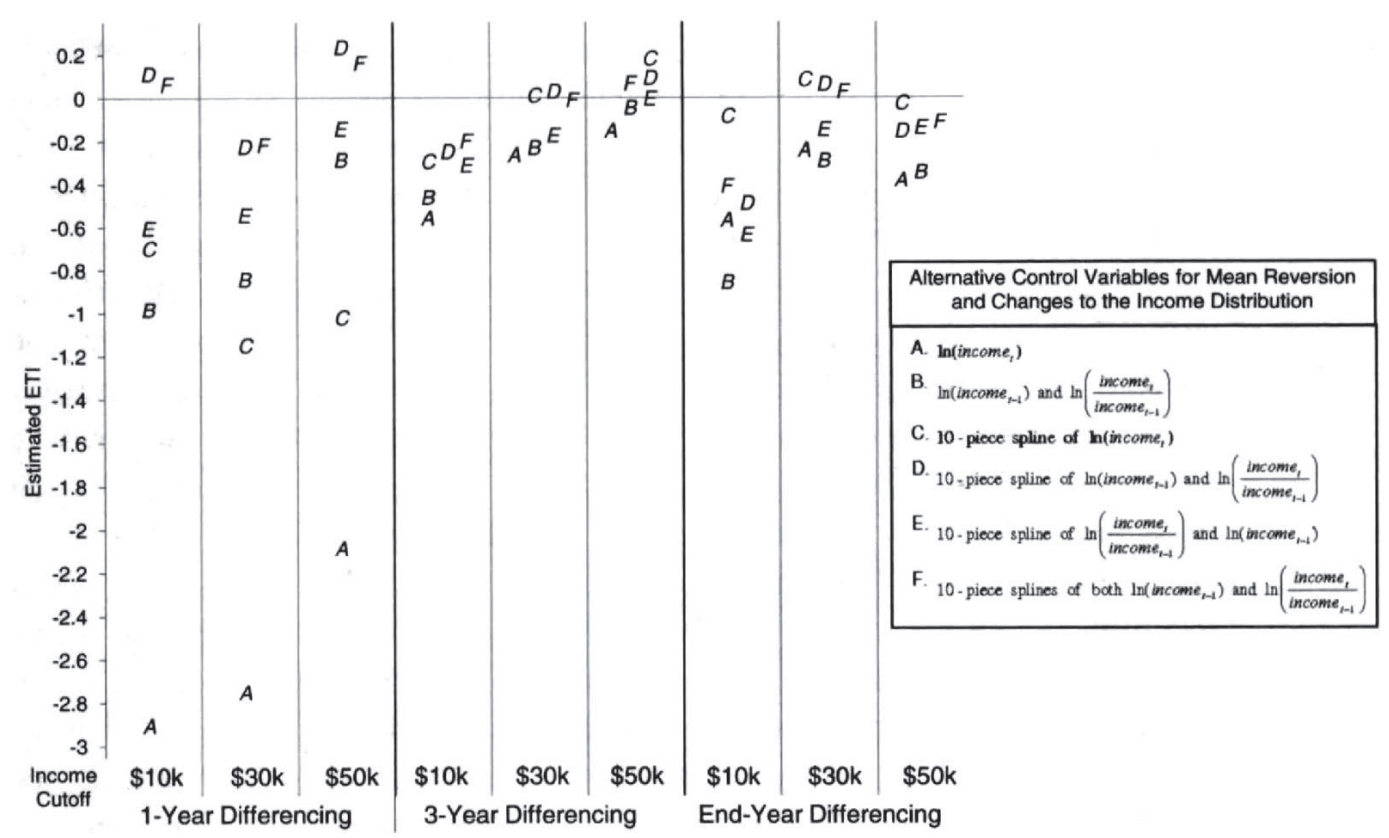

Figure 4. Person-Weighted ETI Estimates for the 1990s

Source; Estimates are based on Statistics of Income data for years 1989 to 1995. Estimates are from 2SLS regressions. Regressions are weighted by the inverse of sampling probabilities and by income (see Section 3 ).

Consistent with Gruber and Saez (2002), Giertz (2007) and others, estimated elasticities are almost always smaller for broader measures of income. Table 4 reports income-weighted elasticity estimates for gross income (which includes exemptions and standard or itemized deductions). Elasticities for broader income measures are likely smaller (than for taxable income) because taxpayers have fewer margins to alter the broader measure and a given change in income represents a smaller percentage of the broader measure. Also, when tax rates change, there is not necessarily an incentive to lower gross income-only taxable income, which is a subset of gross income. ${ }^{26}$ The smaller elasticity estimates for gross income suggest that the responsiveness of itemized deductions may be an important component of the ETI.

\section{Accounting for Adjacent-Year Tax Rate Changes}

Section 3 discussed how including (logs of the) lag and lead changes in the NTR can potentially separate transitory from longer-term income responses. This approach is performed using the sample of paired observations measuring behavior over single-year intervals. Table 5 presents results from specification $\mathrm{F}$, which includes both sets of 10 -piece splines. The estimated short-term response $(0.43)$ is much larger than for the earlier specification that excludes adjacent-year rate changes (0.19), and incorporating the lag and lead rate changes suggests a much larger longer-term response. For example, the estimated coefficients for the lead and

26. In theory, one could have all his/her income in nontaxable forms (e.g., returns from tax-exempt bonds), in which case an increase in tax rates applying to taxable income should not alter behavior. 


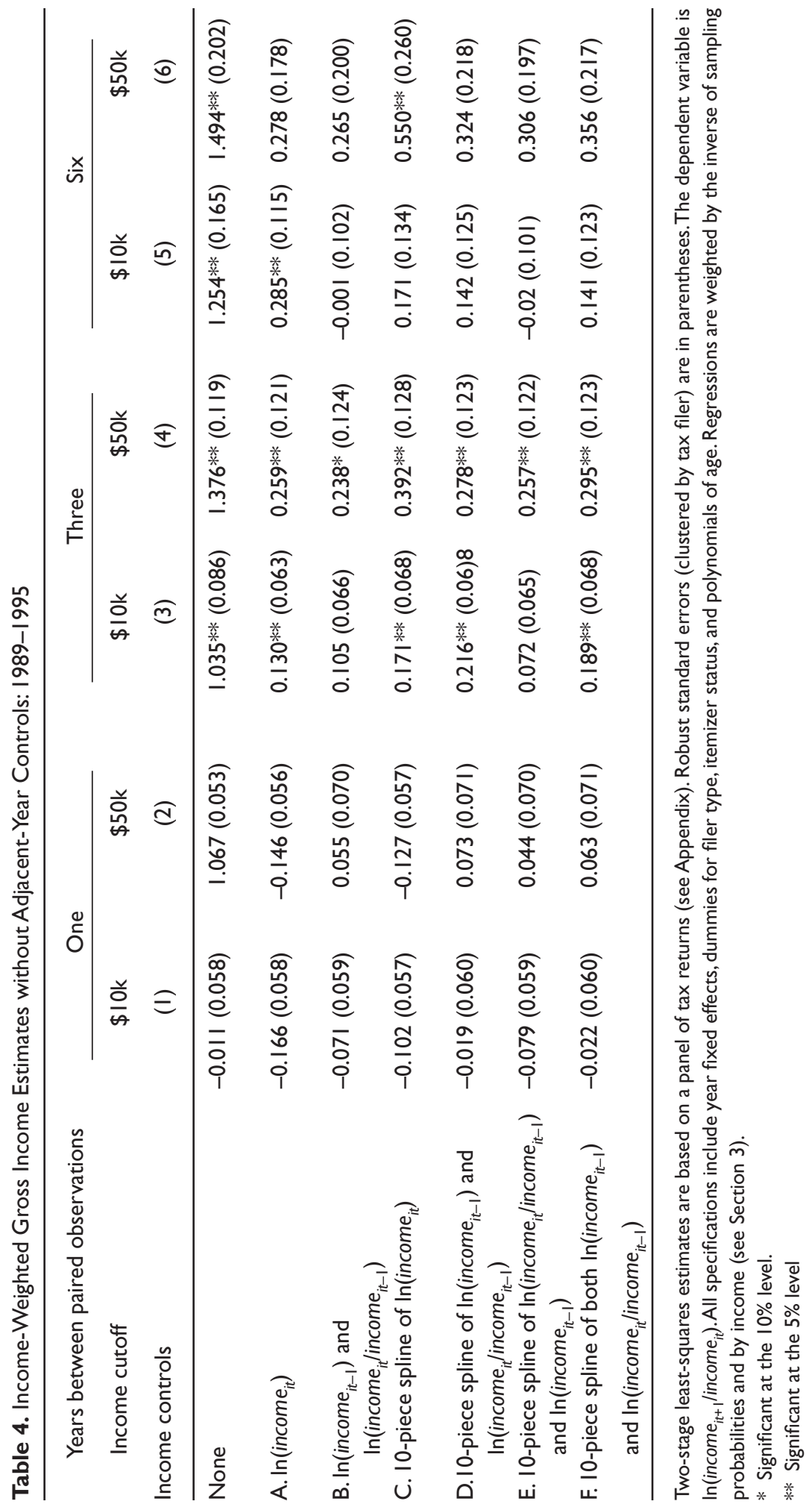


Table 5. Income-Weighted ETI Estimates with Adjacent-Year Controls: 1989-1995

(I)
$\ln \left(\frac{I-\tau_{i t+1}}{I-\tau_{i t}}\right)$
$0.425 * *(0,112)$
$\ln \left(\frac{1-\tau_{i t}}{1-\tau_{i t-1}}\right)$
$0.683^{* *}(0.094)$
$\ln \left(\frac{1-\tau_{i t+2}}{I-\tau_{i t+1}}\right)$
$0.354^{* *}(0.111)$

Two-stage least-squares estimates are based on a panel of tax returns (see Appendix). Robust standard errors (clustered by tax filer) are in parentheses. The dependent variable is $\ln \left(\right.$ income $_{i t+l} /$ income $\left._{i t}\right)$ and two 10-piece splines are included to control for mean reversion and changes to the distribution of income. The regression includes year fixed effects, dummies for filer type, itemizer status, and polynomials of age. The regression is weighted by the inverse of sampling probabilities and by income, and a $\$ 50,000$ baseyear income cutoff is imposed on the sample (see section 3).

** Significant at the $5 \%$ level.

concurrent rate changes sum to 0.78 , and adding to this the estimated coefficient on the lagged rate change raises the overall elasticity to 1.46. This is in stark contrast to findings from Goolsbee (2000) and Hall and Liebman (2000) for executives. ${ }^{27}$ For the first half of the 1990s, Goolsbee reports short-term elasticity estimates often in excess of 1 and much smaller longer-term estimates ranging from 0 to 0.4 (when adding estimated coefficients from the lead and concurrent tax rates). Hall and Liebman argue that even short-term responses may be modest-and that the apparent large short-term elasticity estimates reported by Goolsbee could be due to stock market performance and the exercising of prior stock options. ${ }^{28}$

While in this article this approach yields longer-term estimates that are larger than the majority of estimates found in the more recent ETI literature, these estimates should be treated with caution. Recall from the previous section the alternative interpretations for the lead and lag coefficients. In addition to any delayed or anticipatory response to tax rate changes, these estimated coefficients could be influenced by concurrent tax responses that influence income in adjacent years (where income in an adjacent year is also used in constructing the dependent variable for the preceding or succeeding year). To the extent that estimates for the lead and lag coefficients are driven by this second effect, they should not be interpreted as part of the elasticity. It may be that the lead and lag rate changes are capturing a combination of delayed and anticipatory responses as well as these other effects. It is impossible to tell if or to what degree this is true.

27. A caveat is in order when comparing these results to Goolsbee and Hall and Liebman. In addition to focusing on a select subset of taxpayers, Goolsbee and Hall and Liebman do not use tax return data for their analyses. Because of data limitations, their taxable income measures are not as comprehensive as those calculated using IRS tax data. As a result, their taxable income measures could be better characterized as earned income before deductions. Even the measure of earned income is not comprehensive because it does not include income from other family members or income earned outside the firm (included in the executive database).

28. Heim (2007), in examining the 1990s tax increase, also estimates a model that includes adjacent-year rates changes: however, he differences observations over three-year intervals (instead of over a single year). He reports an estimated coefficient on the concurrent change in the NTR of 1.47, but the estimated coefficients on the lag and lead variables are negative and large in absolute magnitude. Summing all three estimated coefficients yields an overall estimate of -0.31 . 


\section{Conclusion}

This article employs variations of a differencing methodology to panels of IRS tax return data for the 1990s in order to estimate short- and longer-run responses of taxable (and gross) income to changes in tax rates. In addition to varying the time interval over which behavior is measured, sensitivity tests are conducted by exploring different combinations of control variables as well as alternative weighting strategies and methods for separating short- from longer-term responses.

In general, income-weighted estimates are somewhat larger when behavior is measured over three-year intervals as opposed to over one-year intervals. This is in contrast to some of the literature that has found large short-term responses to the 1990s tax changes but smaller longer-term responses. When including the richest set of income controls, income-weighted ETI estimates range from 0.19 when differencing over single-year intervals to 0.33 when differencing over three-year intervals. Estimates from an end-year approach, while sometimes large, are not statistically different from 0 , suggesting that, at least for this period, there is not enough variation to identify responses with just two years of data. Adding adjacent-year tax rates to the model, which could capture delayed and anticipatory responses to tax changes, yields much larger estimates. With this approach, estimates range from 0.43 over the short term and from 0.78 to 1.46 when accounting for delayed and anticipatory responses. However, the lag and lead tax rate changes could also be capturing other factors, cautioning against placing too much stock in these estimates.

While Chetty (2009) provides an alternative explanation for the range of estimates found in the literature, divergence within the income distribution still remains one of the most intransigent obstacles to correctly identifying the ETI. The fact that the divergence in incomes has persisted through periods of both increases and decreases in the level and progressivity of tax rates suggests that it is, in large part, not a direct response to tax changes. However, the possibility that the phenomenon results from a longer-run more nuanced response to the lowering of marginal tax rates on top income since World War II cannot be ruled out (see Piketty and Saez 2007 and Saez and Veall 2005).

While more sophisticated control variables yield more robust estimates, estimates are still sensitive to reasonable a priori specification decisions. This is true throughout the literature and reflects the inherent complexity of separating responses to changes in tax rates from the many other factors that also influence income. A continuing obstacle to identification is that the most sophisticated income controls, which are most likely to adequately control for mean reversion and divergence within the income distribution, are also the most likely to absorb much of the independent variation in tax rates, also needed for identification.

\section{Appendix: U.S. Tax Return Data}

The estimation of behavioral responses of reported income to tax changes relies on the availability of highquality individual income tax data. The IRS's SOI division has created large annual micro data sets of individual tax returns since 1960. The SOI data are stratified random samples that, for the time period examined in this article, include roughly 125,000 tax returns per year and include most of the information reported on tax returns, plus some additional demographic information. Sampling rates vary by income (and other tax return characteristics). The SOI data heavily oversample high-income filers with $100 \%$ sampling rates at the top of the distribution, a key advantage because top incomes play a critical role in determining overall responses to changes in tax rates-especially for this article since the 1990s tax changes were concentrated at the top of the income distribution. 
Selection into the SOI data set is conditional on several factors, including income. More specifically, each individual is assigned a number at random that does not change from year to year. For each year, tax returns are separated into strata based on AGI and the forms and schedules used by the filers. Sampling probabilities vary by strata and reach $100 \%$ for very high income filers. The returns in each stratum are sorted by the randomly assigned values, and the strata sampling probability is used to determine the cut point for inclusion in the sample. Because the individual maintains the same random value over time and because the stratum sampling probability simply determines the cut point for inclusion in the sample, once included in the SOI sample, an individual is automatically included in future years if his income remains the same or if his income increases because this would put him either in the same stratum or in a stratum with a higher sampling probability. Therefore, an individual observed in the base year is much more likely to be observed in the future year if his income rises than if it falls. In fact, the probability that one is observed in two different years is simply the minimum of the strata sampling probabilities for the two years. This raises the potential for spurious correlation between the dependent variable $\left[\ln \left(\right.\right.$ income $_{i t+k} /$ income $\left.\left._{i t}\right)\right]$ and the independent variables, including the tax variable. As noted in Section 3, to avoid this possibility, (paired) observations are weighted by the reciprocal of their probability of appearing in the sample. This same strategy is employed by a number of researchers using these data.

SOI releases a public use file version of annual cross sections of tax returns. However, these files do not include individual identifiers and thus cannot be used for panel data analysis. Additionally, public use files have a lower sampling rate at the very top of the income distribution (1/3 instead of 1$)$ and exclude or blur some variables for those at the top of the income distribution.

\section{References}

Auten, Gerald, and Robert Carroll. 1999. The effect of income taxes on household behavior. Review of Economics and Statistics 81:681-93.

Bakija, Jon. 2006. Documentation for a comprehensive historical U.S. federal and state income tax calculator program. Unpublished paper, Williams College. Accessed online August 9, 2010, from http://www. williams. edu/Economics/papers/bakijaDocumentation_IncTaxCalc.pdf

Burman, Leonard, and William Randolph. 1994. Measuring permanent responses to capital-gains tax changes in panel data. American Economic Review 84:794-809.

Carroll, Robert. 1998. Do taxpayers really respond to changes in tax rates? Evidence from the 1993 Act. Office of Tax Analysis Working Paper 78, U.S. Department of the Treasury.

Chetty, Raj. 2009a. Bounds on elasticities with optimization frictions: A synthesis of micro and macro evidence on labor supply. NBER Working Paper No. 15616. Available online at http://www.nber.org/papers/ $\underline{\mathrm{w} 15616}$

Chetty, Raj. 2009b. Is the taxable income elasticity sufficient to calculate deadweight loss? The implications of evasion and avoidance. American Economic Journal: Economic Policy 2:31-52.

Congressional Budget Office. 2001. Effective federal tax rates. 1979-1997. Washington, DC: Congressional Budget Office.

Congressional Budget Office. 2009. CBO's methods for projecting capital gains realizations. Letter to the Honorable Charles E. Grassley. Washington, DC: Congressional Budget Office. Accessed August 9, 2010, from http://cbo.gov/ftpdocs/70xx/doc7047/02-23-CapitalGains.pdf

Eissa, Nada, and Seth Giertz. 2008. Trends in high-income and behavioral responses to taxation: Evidence from executive compensation and statistics of income data. Working Paper 2006-14. Congressional Budget Office. Accessed August 9, 2010, from http://www.cbo.gov/ftpdocs/77xx/doc7711/2006-14.pdf

Feenberg, Daniel. 2009. A response to Seth H. Giertz. In Tax Policy Lessons from the 2000s, edited by Alan Viard. Washington, DC: AEI Press, pp. 137-44.

Feldstein, Martin. 1995. The effect of marginal tax rates on taxable income: A panel study of the 1986 Tax Reform Act. Journal of Political Economy 103:551-572.

Feldstein, Martin. 1999. Tax avoidance and the deadweight loss of the income tax. Review of Economics and Statistics 81:674-80.

Feldstein, Martin, and Daniel Feenberg. 1996. The effect of increased tax rates on taxable income and economic efficiency: A preliminary analysis of the 1993 tax rate increases. In Tax Policy and the Economy 10, edited by James Poterba. Cambridge, MA: MIT Press, pp. 89-117.

Giertz, Seth. 2007. The elasticity of taxable income over the 1980s and 1990s. National Tax Journal 60:743-68. 
Giertz, Seth. 2009. The elasticity of taxable income: Influences on economic efficiency and tax revenues, and implications for tax policy. In Tax Policy Lessons from the 2000s, edited by Alan Viard. Washington, DC: AEI Press, pp. 101-36.

Goolsbee, Austan. 1999. Evidence on the high-income Laffer curve from six decades of tax reforms. Brookings Papers on Economic Activity 2:1-47.

Goolsbee, Austan. 2000. What happens when you tax the rich? Evidence from executive compensation. Journal of Political Economy 108:352-78.

Gordon, Roger, and Joel Slemrod. 2000. Are 'real' responses to taxes simply income shifting between corporate and personal tax bases? In Does Atlas Shrug? The Economic Consequences of Taxing the Rich, edited by Joel Slemrod. New York: Russell Sage Foundation and Harvard University Press, pp. 240-288.

Gruber, Jonathan, and Emmanuel Saez. 2002. The elasticity of taxable income: Evidence and implications. Journal of Public Economics 84:1-32.

Hall, Brian, and Jeffrey Liebman. 2000. The taxation of executive compensation. In Tax Policy and the Economy 10, edited by James Poterba. Cambridge. MA: MIT Press, pp. 1-44.

Harberger, Arnold. 1964. Taxation, resource allocation, and welfare. In The Role of Direct and Indirect Taxes in the Federal Revenue System, edited by John Due. Princeton. NJ: Princeton University Press, pp. 25-75.

Heim, Bradley. 2007. The elasticity of taxable income: Evidence from a new panel of tax returns. Unpublished paper, Office of Tax Analysis. U.S. Department of the Treasury.

Kopczuk, Wojciech. 2005. Tax bases, tax rates and the elasticity of reported income. Journal of Public Economics 89:2093-119.

Kopczuk, Wojciech, Immanuel Saez, and Jae Sotig. 2010. Earnings inequality and mobility in the United States: Evidence from Social Security data since 1937. Quarterly Journal of Economics 125:91-128.

Lindsey, Lawrence. 1987. Individual Taxpayer Response to Tax Cuts: 1982-1984, with Implications for the Revenue Maximizing Tax Rate. Journal of Public Economics 33:173-206.

Madrian, Brigitte, and Dennis Shea. 2001. The power of suggestion: Inertia in 401(k) participation and savings behavior. Quarterly Journal of Economics 116:1149-87.

Moffitt, Robert, and Mark Wilhelm. 2000. Taxation and the labor supply decisions of the affluent. In Does Atlas Shrug? The Economic Consequences of Taxing the Rich, edited by Joel Slemrod. New York: Russell Sage Foundation and Harvard University Press, pp. 193-234.

Navratil, John. 1995. The Tax Reform Act of 1986: New evidence on individual taxpayer behavior from panel tax return data. In Essays on the Impact of Marginal Tax Rate Reductions on the Reporting of Taxable Income on Individual Tax Returns. Doctoral dissertation. Harvard University.

Parcell, Ann. 1995. Income shifting in responses to higher tax rates: The effects of OBRA 93. Unpublished paper. Office of Tax Analysis. U.S. Department of the Treasury.

Piketty, Thomas, and Emmanuel Saez. 2003. Income inequality in the United States, 1913-1998. Quarterly Journal of Economics 118:1-39.

Piketty, Thomas, and Emmanuel Saez. 2007. How progressive is the U.S. federal tax system? A historical and international perspective. Journal of Economic Perspectives 21:3-24.

Ramsey, Frank. 1927. A contribution to the theory of taxation. Economic Journal 37:47-61.

Saez, Emmanuel. 2004. Reported incomes and marginal tax rates, 1960-2000: Evidence and policy implications. In Tax policy and the Economy 18. edited by James Poterba. Cambridge. MA: MIT Press, pp. 117-73.

Saez, Emmanuel, Joel Slemrod, and Seth Giertz. 2009. The elasticity of taxable income with respect to marginal tax rates: A critical review. NBER Working Paper No. 15012. Accessed August 9. 2010, from http://www. nber.org/papers/w15012

Saez, Emmanuel, and Michael Veall. 2005. The evolution of high incomes in North America: Lessons from Canadian evidence. American Economic Review 95:831-49.

Sammartino, Frank, and David Weiner. 1997. Recent evidence on taxpayers' response to the rate increases in the 1990s. National Tax Journal 50:683-705.

Slemrod, Joel. 1990. The economic impact of Tax Reform Act of 1986. In Do Taxes Matter? The Impact of the Tax Reform Act of 1986, edited by Joel Slemrod. Cambridge. MA: MIT Press, pp. 1-12.

Slemrod, Joel. 1996. High income families and the tax changes of the 1980s: The anatomy of behavioral response. In Empirical Foundations of Household Taxation, edited by Martin Feldstein and James Poterba. Chicago: University of Chicago Press, pp. 169-89.

Slemrod, Joel, and Wojciech Kopczuk. 2002. The optimal elasticity of taxable income. Journal of Public Economics 84:91-112.

Slemrod, Joel, and Shlomo Yitzhaki. 2002. Tax avoidance, evasion, and administration. In Handbook of Public Economics 3, edited by Martin Feldstein and Alan Auerbach. Amsterdam: Elsevier Science, pp. 1423-70. 